\title{
Memórias do futebol brasileiro
}

\author{
JOÃO MÁXIMO
}

$\mathrm{O}$

FUTEBOL BRASIleiro fez 100 anos em 1995, mas ninguém come-

morou. Não houve um grande jogo internacional, nenhum torneio, nem uma festa, nada que lembrasse a data. Até mesmo nossas emissoras de televisão - sempre tão atentas às efemérides - deixaram o aniversário passar em branco. Se produziram especiais dedicados ao futebol, eles nada tinham a ver com os 100 anos. Afinal, como justificou um de seus produtores, quem garantia que eram mesmo 100 anos? Quem disse que nosso futebol só começou a existir 1895? Não teria a bola rolado antes pelos campos deste imenso país?

Certamente, há algo de arbitrário na data que os historiadores elegeram para assinalar o nascimento do futebol brasileiro. Mas, arbitrária que seja, é a que melhor cabe como ponto de partida para tudo o mais. Nenhuma outra nos fala tão bem de quando, onde, como e, principalmente, por que o futebol brasileiro nasceu. Ou por que, nascendo de uma forma, tornou-se adulto de outra.

Foi realmente em 1895 que Charles Miller, paulistano filho de ingleses, voltou de Southampton depois de ter cursado a Banister Court School. Filhos de boas famílias, como se dizia, iam estudar na Europa, pouco importava que já tivéssemos bons colégios por aqui. E, sobretudo, se eram descendentes de europeus, faziam as malas tão logo completassem a idade para cursar o ginásio. Caso de Charles. Que foi, estudou, conheceu a terra dos pais, fez amigos e, nas horas vagas, descobriu um novo e fascinante brinquedo: the football.

O esporte já era então obrigatório nos recreios escolares britânicos. Isso desde a década de 1840, quando a rainha Vitória, aconselhada pelo pedagogo Thomas Arnold, pôs fim à proibição soberana que, por séculos, seus antecessores andaram impondo ao mass football, jogo de rua, violento, às vezes fatal, que vinha de antiga tradição: a da disputa de uma bola de bexiga de boi, envolvida em couro, que o sapateiro de Derby atirava ao alto na terça-feira gorda, para que dois times - 50 ou mais jogadores da cada lado - tentassem fazê-la passar pela porta da cidade defendida pelo time adversário. Ou seja, o goal. Para tanto, valia-se de tudo, socos, pontapés, cotoveladas, gravatas, golpes sujos. Consta que essa primitiva peleja teria sua origem em um episódio ocorrido quando 
da expulsão dos dinamarqueses de solo britânico no século XI. Para comemorar o feito, os habitantes de Derby teriam organizado um jogo usando como bola o crânio de um oficial invasor morto em combate. Por menos que se acredite nessa versão algo sinistra, foi mesmo como comemoração cívica que o primeiro sapateiro de Derby começou a atirar a bola ao alto, uma vez por ano, nas festas do condado.

Mas por que só então a rainha Vitória decidira que os jovens ingleses poderiam e até deveriam se entregar a esporte tão primitivo, tão bárbaro? A idéia, já vimos, foi de Arnold. Como as escolas oficiais inglesas começavam a ser freqüentadas por meninos de uma classe média em ascenção, os nobres de verdade se misturando com os que tinham dinheiro para comprar nobreza, o pedagogo previu que idéias novas, reformistas, revolucionárias mesmo, poderiam contaminar os futuros homens do Império britânico. Com o futebol, os meninos não perderiam tempo conversando nos recreios, trocando idéias; os nobres poderiam ser influenciados pelos plebeus, cabeças se fazendo, segundo Arnold, na direção errada. Além disso, o que haveria de mais eficaz e menos perigoso para canalizar as energias dos jovens, 11 de um lado, 11 de outro, correndo atrás de uma bola, brigando por ela durante a hora do recreio?

Quando Charles Miller voltou para São Paulo, trazendo na bagagem camisa, calção, chuteiras e duas bolas oficiais, porém, o futebol já deixara de ser atividade escolar alienante para se transformar em esporte organizado, difundido entre clubes e universidades. Charles voltou em 1895, mas em 26 de outubro de 1863 já havia sido fundada na Freemason's, taberna da Great Queen's Street, centro de Londres, The Football Association, a entidade que até hoje rege o futebol na Inglaterra. Já existiam, portanto, as regras, os grandes clubes, os campeonatos, as taças. Quando Charles voltou, enfim, o futebol já era um esporte e não um antídoto de reformas sociais.

Mas voltemos ao Brasil com Charles. Esqueçamos os nascimentos não documentados, que nos falam de holandeses jogando bola nas areias de Recife em 1870, de ingleses improvisando rachas na praia da Glória carioca em 1874, dos marinheiros do Criméia fazendo o mesmo num capinzal próximo da residência da princesa Isabel em 1878, de funcionários de uma firma paraense de navegação enfrentando os de uma companhia de gás na Belém de 1890, além de empresários ingleses que muito antes, em 1876, já haviam ensaiado seus dribles no interior de São Paulo. Esqueçamos tudo isso para nos limitarmos ao que está devidamente documentado: o primeiro match em terra brasileira promovido por Charles 
Miller - com uma daquelas bolas, num terreno baldio da várzea do Carmo, entre as ruas Santa Rosa e do Gasômetro - na manhã de domingo, 14 de abril de 1895. Esqueçamos os demais possíveis nascimentos para ficarmos com este que, além de documentado, contém, mais que qualquer outro, a verdadeira semente do futebol brasileiro. Sim, porque tal semente foi plantada em terreno muito mais nobre do que um campinho de várzea pode sugerir: o jardim da alta classe média paulistana.

Lembremos que o Brasil do fim do século XIX era um país em busca de caminhos. Nisso, mudou pouco desde então. Em 1895, o ano que nos interessa aqui, tínhamos menos de oito décadas de Independência, apenas seis de República e não mais que sete de Abolição. Portanto, o país ainda estava todo por fazer. A capital federal não era exatamente uma cidade maravilhosa. Como a descreve Luiz Edmundo em $O$ Rio de Janeiro do meu tempo:

"A cidade é um monstro onde as epidemias se albergam dançando sabats magníficos, aldeia melancólica de prédios velhos e acaçapados, a descascar pelos rebocos, vielas sórdidas cheirando mal, exceção feita à que se chama rua do Ouvidor, onde o homem do 'burro-sem-rabo' cruza com o elegante da região tropical, que traz no mês de fevereiro sobrecasaca preta de lã inglesa e dilui-se em cachoeiras de suor. O povo está sem instrução. A indústria, desprotegida. Os serviços públicos, de molas perras..."

São Paulo era melhor, mas não muito. Tinha o café, tinha as indústrias, tinha uma sociedade patriarcal comprometida com o progresso. Mas, a exemplo do Rio de Janeiro, também tinha pobreza. Ou melhor, uma população desvalida, perto de miserável, nada semelhante ao "elegante da região tropical" de que nos fala Luiz Edmundo a propósito da capital federal. Na São Paulo de 1895 (aliás, como em qualquer época ou lugar), povo era povo. E elite, elite. Tinha mesmo tintas de nobreza a elite paulistana, incluindo condes, barões, duques, títulos conseguidos menos por genealogia nobiliárquica do que pelo prestígio que o dinheiro podia comprar. Alguns até brasões ostentavam. Educavam seus filhos nos melhores colégios, faziam as filhas se casarem com jovens de sobrenomes ilustres como os seus, impunham-se enfim como cérebro e coração do núcleo familiar. A elite paulistana era mais numerosa e mais abastada que a carioca. Muitos de seus patriarcas vinham da Europa ou descendiam de europeus: italianos, alemães, portugueses, suíços, ingleses. Como os introdutores do futebol nos principais centros brasileiros: Charles Miller, em São Paulo, e Oscar Cox, no Rio. 
Foi com jovens de boas famílias como a sua, até então interessados em críquete, golfe, tênis e similares, que Charles plantou a semente. Ensinou-lhes os fundamentos do futebol, dividiu-os em dois times, escalou um dos seus amigos para juiz, outro para bandeirinha, e lá foram todos fazer história na várzea do Carmo. Depois, realizaram novos jogos em campo literalmente mais nobre: o gramado da chácara da também britânica família Dooley, no bairro do Bom Retiro. Daí, sempre entre a elite, foram surgindo os primeiros times de verdade. Em 1896, o São Paulo Athletic Club, fundado oito anos antes, seria o primeiro a aderir ao novo esporte, logo seguido do Sport Club Germania (1889), de Mackenzie Athletic Association (1898), Sport Club Internacional (1898), Clube Atlético Paulistano (1900), já com nome aportuguesado. Em Campinas, fundou-se a Associação Atlética Ponte Preta (1900). No Rio de Cox, o Fluminense Foot-ball Club (1902), o Rio Foot-ball Club (1902), o Botafogo Foot-ball Club, o America Foot-ball Club, o Bangu Athletic Club (os três últimos em 1904). Flamengo e Vasco da Gama já existiam desde o fim do século, ambos dedicando-se ao remo: o primeiro, só criaria seu departamento de futebol em 1911; o segundo, em 1923. Em Porto Alegre, foi fundado o Esporte Clube Rio Grande (1900); em Minas, o Sport Club Belo Horizonte (1904); em Recife, o Club Náutico Capeberibe (1901); em Salvador, o Vitória Foot-ball Club (1905). Vale ressaltar que há apenas um ponto comum entre todos os momentos dessa gênese: aqui e ali o futebol brasileiro nasceu como brinquedo de menino rico. Ou quase.

Muito diferente, por exemplo, do que ocorreu no Uruguai. Se toda a primeira infância do futebol brasileiro - de 1895 até o fim da terceira década do século - foi vivida por gente socialmente bem situada, culta, afinada com os elegantes da região tropical do Rio e com os patriarcas enobrecidos de São Paulo, no Uruguai suas raízes são profundamente populares. Os ingleses que gerenciavam as indústrias de Montevidéu fizeram o mesmo que Thomas Arnold aconselhara à rainha Vitória: usar o futebol como instrumento de alienação. Enquanto os operários, em seus dias e horas de folga, gastassem suas energias correndo atrás da bola, não pensariam em reivindicar maiores salários e melhores condições de trabalho. Como Arnold, os gerentes estimulavam os trabalhadores à prática de esporte, notadamente do futebol, como um gesto político. Bem diferente do Brasil, razão pela qual os primeiros craques uruguaios eram homens do povo, muitos deles negros, e os brasileiros, pelo contrário, eram os Miller, os Dooleys, os Cox, os Nobiling, grã-finos do Rio, de São Paulo, das grandes cidades. Por tal razão, o futebol uruguaio (também o argentino, outro de origem mais popular que o nosso) seria por muito tempo tecnicamente superior ao brasileiro. 
É verdade que essa tese - a do melhor futebol ser um privilégio do homem do povo - desperta controvérsias. Sociólogos, antropólogos, entre outros estudiosos, têm denunciado sua falta de fundamento científico. Mas, defendida por Gilberto Freyre no prefácio do livro de Mário Filho O negro no futebol brasileiro, e por este corroborada nas páginas seguintes, ela não deixa de ter sentido. Mais que isso, tem contornos de verdade. E um dos seus mais eloqüentes pontos de apoio é, ninguém menos que, o primeiro craque a surgir no Brasil: Arthur Friedenreich. Filho de alemão com negra brasileira, dividindo sua infância entre o clube fechado do pai e as peladas democráticas do bairro da mãe, o mulato de olhos verdes foi, até fins dos anos 20 , uma espécie de estranho no ninho, um homem do povo vestindo a mesma camisa dos jovens da elite, fazendo-se campeão e artilheiro, chegando à seleção paulista e depois à brasileira, tudo isso numa época em que nenhum de seus europeizados companheiros e adversários jogava a metade de seu futebol.

É muito em função disso que se pode dividir a história do futebol brasileira em várias fases. Em outras palavras, em fases que refletem o que o esporte vem representando ao longo do tempo na sociedade brasileira, sucessivamente como passatempo de poucos, esporte da elite, elemento de integração, paixão popular, profissão, meio de afirmação nacional, instrumento político, uma arte brasileira e finalmente como negócio milionário e global dentro do qual o Brasil representa importante papel.

É verdade que a história do futebol brasileiro ainda está para ser contada. Ainda não se dedicou a ela o tempo, a abrangência, o aprofundamento devidos, um descaso típico de um país sem memória que deixa passar em branco os cem anos de seu esporte nacional. Mas, sem pretendermos contar aqui essa história, ousamos definir cada uma daqueles fases, de resto tão arbitrárias quanto o ano de 1895 , mas talvez legítimas o bastante para vermos como o menino que nasceu rico chegou onde chegou.

Do futebol brasileiro como passatempo de poucos e como esporte da elite, já falamos. Basta acrescentar que o homem do povo não teve acesso a ele nessa primeira infância. Embora um ou outro pobre, um ou outro negro, moços que de forma alguma poderiam freqüentar um São Paulo, um Fluminense, pouco a pouco fosse conquistando seu lugar nos clubes de primeira divisão, era forte a oposição que se fazia a eles. O futebol era declaradamente racista. Em 1921, por exemplo, ninguém menos que o presidente da República, Epitácio Pessoa, recomendou que não se incluíssem mulatos na seleção brasileira que iria a Buenos Aires para o Campeonato Sul-Americano. Era preciso projetar outra imagem nossa no exterior, alegava o alto mandatário. Uma delegação de futebol 
não deixava de representar o país. E era absolutamente imperioso que o país fosse representado por sua "melhor sociedade". Uma recomendação que deixava ainda mais indignado o romancista Lima Barreto, o mulato de Todos os Santos que um ano antes, justamente pelo caráter discriminatório do esporte, fundara no Rio a Liga Contra o Futebol. Opunha-se, evidentemente, ao acadêmico Coelho Neto, homem do aristocrático Fluminense, cujos filhos eram craques do clube (um deles, Preguinho, ainda chegaria à seleção brasileira e marcaria nosso primeiro gol numa Copa do Mundo). Para Coelho Neto, o futebol era um magnífico forjador de caráter. Em suma, um passatempo de poucos, um esporte de elite.

Mas mesmo nos anos 20 - em que um Vasco da Gama podia ser expulso da primeira divisão carioca por ousar ser campeão com um time repleto de negros - já se notava certa integração entre as classes e as raças. Em São Paulo, o Corinthians, fundado em 1910, seguia fiel às sua origens nitidamente populares. No Rio, além do Vasco da Gama, clubes como o América e o Bangu pareciam não concordar com Epitácio Pessoa. É fato que em outras cidades as coisas não eram tão simples (Grêmio Porto-Alegrense, por exemplo, proibia em seus estatutos que negros the vestissem a camisa, proibição que só caducaria nos anos 50). Mas, de qualquer forma, o brasileiro - torcida e jogador, jogador e jogador - ia-se integrando por meio do futebol.

Quando e como o esporte terá virado paixão popular? É evidente que não aconteceu da noite para o dia. Mas na heróica vitória brasileira sobre uruguaios, no final do Campeonato Sul-Americano de 1919, disputado no recém-inaugurado estádio do Fluminense, já havia menos de esporte que de paixão. Friedenreich marcou o gol da vitória na terceira prorrogação, foi carregado nos ombros da torcida pelas ruas da cidade, teve as chuteiras expostas numa joalheria e consagrou-se como ídolo maior, cognominado El Tigre pelos adversários. O futebol nunca estivera tão na alma do povo. Dali em diante, a paixão só cresceria. Torcer tornar-se-ia quase uma religião.

O profissionalismo, regime que seria oficialmente implantado em 1933, foi outro divisor de águas. E dos mais importantes. Uruguaios e argentinos já o adotavam havia algum tempo. Basicamente, como modo de evitar que seus melhores jogadores de origem italiana - os Nazassi, os Monti, os Colaussi, os Guaita, os Orsi e os Mascheroni - corressem atrás das liras italianas e se transferissem para o Torino, o Milan, o Juventus, clubes que acabariam fazendo de alguns deles, oriundi naturalizados, bicampeões mundiais em 1934-1938. 


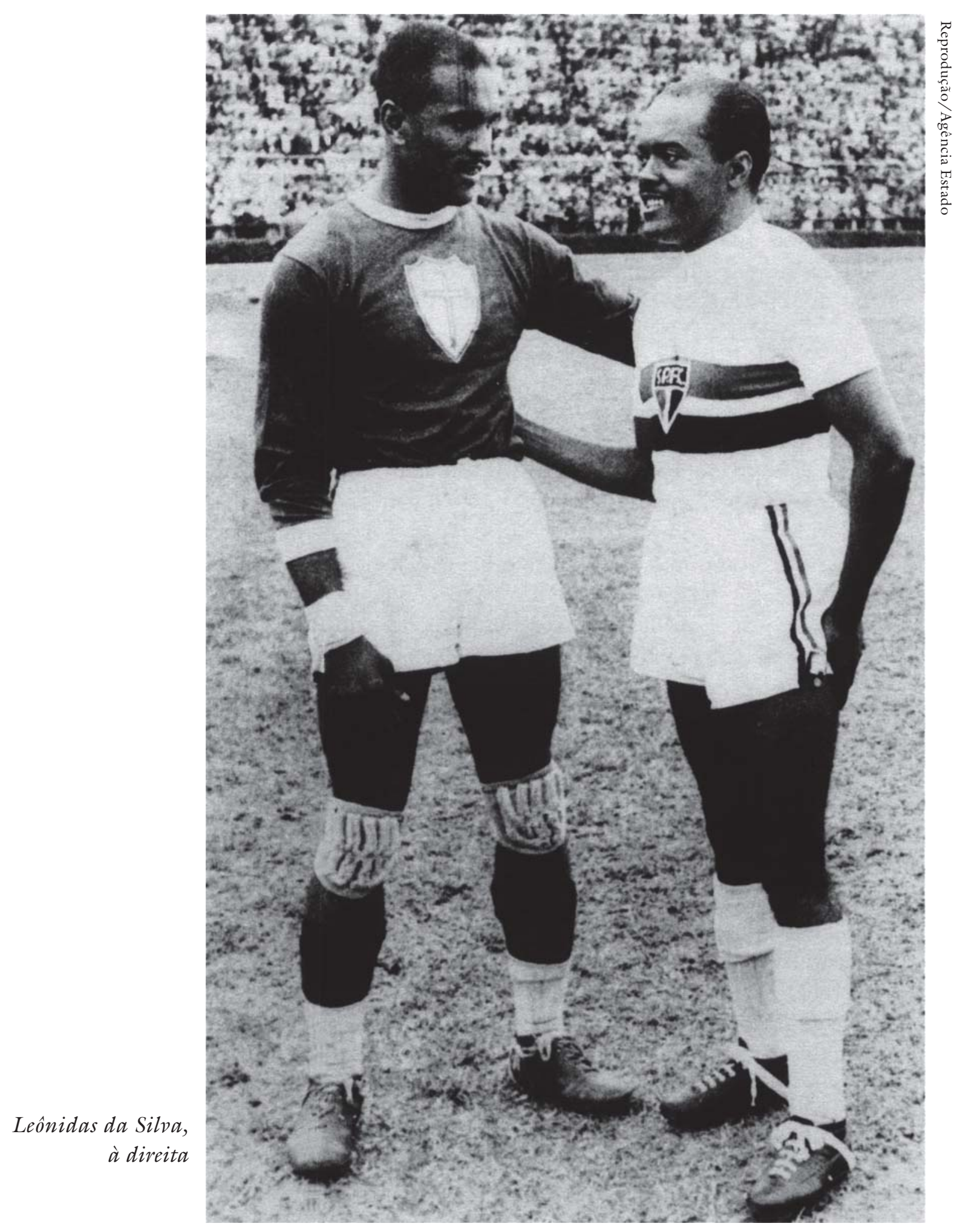

Estudos Avançados 13 (37), 1999 
No Brasil, estranho que pareça, o avanço profissionalista teve como causa uma idéia conservadora. Os clubes que perdiam campeonatos por se negarem a ter em seus times jogadores negros (e seus times eram formados obrigatoriamente por sócios-atletas, com direito a freqüentar as sedes sociais) decidiram decretar o novo regime. Assim, poderiam arregimentar jogadores de qualquer raça ou condição social, contratados como empregados, sem precisarem macular seu quadro social. Não foi por acaso que as elites do Fluminense e do São Paulo estavam entre os líderes do movimento profissionalista. O que, por sinal, resultou em séria cisão no futebol brasileiro, só sepultada com a reunificação de 1937.

A profissionalização abriu definitivamente o caminho para que os primeiros gênios do futebol brasileiro, a suceder Friedenreich, entrassem em campo. Fausto dos Santos, Domingos da Guia, Leônidas da Silva, Waldemar de Brito e depois uma longa e ilustre galeria de Zizinho a Pelé. Integrado, profissionalizado e temperado na paixão, o futebol brasileiro seria devidamente coroado em $1970 \mathrm{com}$ o tricampeonato mundial no México e a conquista definitiva da Taça Jules Rimet. Foi uma caminhada vitoriosa, mas nem por isso livre de malogros e frustrações. Porque, no meio dela, à medida que amadurecia dentro do campo, o futebol brasileiro via-se vítima de distorções nas arquibancadas. Talvez porque o país tivesse tão pouco do que se orgulhar, o futebol converteu-se num equivocado meio de afirmação nacional. Ganhar uma Copa do Mundo passou a ser, desde nosso terceiro lugar na de 1938, uma espécie de termômetro: era isso que iria dizer se éramos ou não uma grande nação. Claro, não pensavam assim os mais lúcidos, os mais bem informados, os que viam o Brasil com olhos que não os do torcedor. Mas para este, ser campeão mundial era o atestado de nossa grandeza. Motivo de ter ele encarado como tragédia nacional a derrota para os uruguaios em 1950, em pleno Maracanã erguido justamente para festejarmos a vitória. Motivo também de duvidarmos de nosso talento, de nossos brios, de nosso patriotismo, quando da derrota para os húngaros em 1954. Os equívocos se repetiriam até nos tão ansiados dias de glória, as conquistas de 1958, 1962 e 1970. "Com o brasileiro não há quem possa...", cantava-se após a primeira. "Ninguém segura este país!”, exclamava-se depois da última.

Muito tempo passaria até que o torcedor brasileiro começasse a perceber que a seleção brasileira era uma coisa e o Brasil, outra. Que o futebol, eterna paixão, não era o que o dramaturgo Nélson Rodrigues rotulou de "a pátria em chuteiras". Era, sim, um brinquedo levado muito a sério. 
Um brinquedo que sempre foi usado pela política. Epitácio Pessoa não foi o primeiro a ver na seleção brasileira uma espécie de representação diplomática. Nem seria o último. Mas nunca futebol e política andaram tão de mãos dadas por aqui como nos anos que se seguiram ao tri de 1970. Para começar, o general presidente era um torcedor confesso, desses de acompanhar os jogos com radinho de pilha colado ao ouvido. Naqueles tempos de regime militar, havia apenas dois partidos no Brasil, a Arena (do governo) e o MDB (de uma oposição controlada). Passada a Copa do Mundo do México, Brasília interveio na CBD (hoje CBF) forçando João Havelange a renunciar à sua presidência e nomeando para substituí-lo o Almirante Heleno de Barros Nunes, não por coincidência presidente da Arena fluminense. A partir daí os participantes do Campeonato Brasileiro foram sendo indicados por convite da CBD e não por critérios técnicos. Dentro do humor que ainda lhe era permitido, o torcedor cunhou um dito não desprovido de fundamento: "Onde a Arena vai mal, um clube no Nacional..." Isto é, aos estados ou cidades em que o partido do governo estava ameaçado de perder as eleições, o almirante tentava agradar, arrebanhar votos, convidando mais de um clube para disputar o Campeonato. Como resultado, a competição chegou a ter mais de 70 participantes, um gigantismo que muito contribuiu para um período de declínio técnico do futebol brasileiro. Com o excesso de jogos, os times já não tinham tempo para treinar, recuperar seus jogadores do desgaste físico, investir como antes nas divisões de base. A renovação de craques, antes um de seus trunfos, fazia-se mais lentamente. Se a Copa do Mundo era mesmo um termômetro (não do país, mas da qualidade do futebol), está explicado por que a seleção brasileira ficaria 24 anos sem ao menos chegar a uma final.

Mas não há como não reconhecer que o passatempo de poucos, esporte de elite, cresceria para ser uma instituição brasileira. Nenhum patriotismo tolo, nenhuma xenofobia descabida, nada disso deve ser confundido com a afirmação de que o futebol brasileiro chegaria ao fim do século como o que mais e melhor contribuiu para o encanto do jogo, o aperfeiçoamento de sua técnica, a elevação do esporte às dimensões de pura arte (pelo menos é assim que se referem ao futebol brasileiro nossos cronistas mais poéticos e arrebatados, criando, com o pensamento em nossos incontáveis gênios da bola, o termo futebol-arte). Nenhum, enfim, voou tão alto.

Muitos fatos o atestam: nenhum país ganhou tantos títulos mundiais, nenhum outro serviu de berço a tantos craques extra-classe, nenhum esteve presente em todas as Copas do Mundo, nenhum é tão res- 
peitado, admirado e temido por seu futebol. O negócio milionário e global em que o futebol se transformou nesta última década não seria o que é sem o Brasil. Podemos formar uma seleção em nível mundial só com jogadores que atuam em clubes da Itália, da Espanha, da Alemanha, da Inglaterra, da França, da Holanda. Todos valendo seu peso em ouro. Já podemos nos orgulhar disso. Agora, mais maduros, sem os equivocados exageros que nos levaram um dia a medir o Brasil pela qualidade de seu jogo. Já nos sabemos grandes ou pequenos, independentemente de Pelé ou de nossos cabeças-de-bagre. Ainda bem.

Mas a história do futebol brasileiro, que ainda está para ser contada, tem sido tão rica, tão emocionante, tão feita de grandes momentos, que é mesmo imperdoável não termos comemorado com todas as pompas, em 1995, o centenário do primeiro chute de Charles Miller naquela várzea paulistana.

João Máximo é jornalista de O Globo, jornal com sede na cidade do Rio de Janeiro (RJ). 